\title{
Organization of costs with medical and pharmaceutical supplies in integrated care teams
}

Organização dos custos com material de consumo clínico e farmacêutico

nas equipas de cuidados integrados

Organización de los costes de material de consumo clínico y farmacêutico

en los equipos de cuidados integrados

Maria Margarida Leitão Filipe*; Abel Paiva e Silva**; Suzete Gonçalves***

\begin{abstract}
Background: Public policies on cost reduction and control have resulted in early inpatient discharge, followed by the provision of home care by integrated continuous care teams (ICCTs).

Objectives: To identify ICCT clusters that report costs deriving from the use of medical and pharmaceutical supplies (MPSs).

Methodology: A cluster analysis was performed through a two-step method, an exploratory instrument designed to reveal natural clusters considering a dataset framework.

Results: Two clusters were identified. The most representative cluster - lower consumption of wound care supplies comprised 138 cases (86.8\%), whereas the other cluster - higher consumption of wound care supplies - comprised only 21 cases $(13.2 \%)$.

Conclusion: This study identified that the costs with MPSs in the client cluster with higher consumption of wound care supplies always exceed the overall median value.
\end{abstract}

Keywords: health care costs; long-term care; clusters

\section{Resumo}

Enquadramento: Atendendo às pressões para a gestão e redução dos custos no contexto do setor público, os doentes têm altas mais precoces e os cuidados são prestados em contexto domiciliário através das equipas de cuidados continuados integrados (ECCI). Objetivos: Identificar os agrupamentos de casos que nas ECCI têm custos associados à utilização de material de consumo clínico e farmacêutico (MCCF).

Metodologia: Análise de cluster através do método TwoStep que é uma ferramenta exploratória projetada para mostrar agrupamentos naturais (clusters) dentro de uma série de dados que de outra maneira não seriam aparentes.

Resultados: Foram identificados 2 grupos. O agrupamento de maior dimensão menor consumo de materiais de tratamento de feridas agrega 138 casos (86,8\%), enquanto o agrupamento maior consumo de materiais de tratamento de feridas agrega apenas 21 casos $(13,2 \%)$.

Conclusão: Da análise a estes agrupamentos, verificamos que o grupo de cliente onde há maior consumo de materiais de tratamento de feridas apresenta sempre valores para os custos com os MCCF superiores ao da mediana global.

Palavras-chave: custos de cuidados de saúde; assistência de longa duração; clusters

\footnotetext{
$\mathrm{Ph}$ D, Supervising Nurse, Local Health Unit of Matosinhos, 4454-509, Porto, Portugal [margaridafilipe61@gmail.com]. Contribution to the article: literature search; data collection; margaridafilipe61@gmail.com]. Contribution to the article: literature search; data collection;
statistical treatment and assessment; data analysis and discussion; article writing. Address for statistical treatment and assessment; data analysis and discussion; article writing. Address
correspondence: Rua Alberto Serpa - $209-4^{\circ}{ }^{\circ}$ Hab. 4, 4100-010, Sra. Hora, Porto, Portugal. correspondence: Rua Alberto Serpa - 209 - 4. $^{\circ}$ - Hab. 4, 4100-010, Sra. Hora, Porto, Portugal.
** Ph.D., Coordinating Professor, Porto Nursing College, 4200-072, Porto, Portugal [abel@esenf. pt]. Contribution to the article: statistical treatment and assessment; data analysis and discussion. *** Ph.D., Researcher, Center of Study and Research in Health - CEISUC, Faculty of Economics, University of Coimbra [suzetegonc@gmail.com]. Contribution to the article: data analysis and discussion.
}

\section{Resumen}

Marco contextual: Atendiendo a las presiones para gestionar y reducir costes en el ámbito del sector público, los enfermos reciben el alta antes y los cuidados se prestan en el ámbito doméstico a través de los Equipos de Cuidados Continuados Integrados (ECCI). Objetivos: Identificar los grupos de casos en los que los ECCI tienen costes asociados a la utilización de material de consumo clínico y farmacéutico (MCCF).

Metodología: Análisis de clústeres a través del método TwoStep, que es una herramienta exploratoria enfocada a mostrar grupos naturales (clústeres) dentro de una serie de datos que de otra forma no serían aparentes.

Resultados: Se identificaron 2 grupos. El grupo de mayor dimensión - Menor consumo de material de tratamiento de heridas - presenta 138 casos (86,8\%), mientras que el grupo Mayor consumo de material de tratamiento de heridas presenta únicamente 21 casos (13,2 \%). Conclusión: Del análisis de estos dos grupos verificamos que el grupo de cliente donde hay mayor consumo de material de tratamiento de heridas presenta siempre cifras para los costes relativos a los MCCF superiores al de la mediana global.

Palabras clave: costos de la atención en salud; cuidados a largo plazo; análisis por conglomerados

Received for publication: 18.01.16 Accepted for publication: 18.07 .16 


\section{Introduction}

This study results from a research study conducted within the scope of the $5^{\text {th }}$ Doctoral Program in Nursing at the Universidade Católica Portuguesa (area of specialization of Management of Health Care Centers and Nursing Services). This study aims to identify the clients of integrated continuous care teams (ICCTs) according to the cost with different medical and pharmaceutical supplies used in Integrated continuous care interventions.

Aging and the increasing burden of debilitating chronic conditions that result in high levels of self-care dependence bring about major implications to the social welfare and health system. Although aging is not synonymous with disease and dependence, there is a considerable prevalence of chronic diseases among older people (Instituto Nacional de Estatística [INE], 2012). Comorbidities are very common and, in most OECD countries, it represents more than $50 \%$ of the disease burden (Organisation for Economic Co-operation and Development [OECD], 2011).

The Portuguese Observatory on Health Systems (Observatório Português dos Sistemas de Saúde [OPSS]) estimates that 110,355 people are dependent at home, in some form of self-care, and that 48,450 of them will develop with high levels of dependence, i.e. become bedridden (OPSS, 2015).

A better knowledge of the population to whom ICCTs provide care taking into account the resources used throughout the whole care process contributes to building a contracting and financing model based on the complexity of the population being cared for and the performance of the teams providing care.

In this article, we will present clusters identified through the analysis of the costs with medical and pharmaceutical supplies in the interventions performed by several professionals from ICCTs.

This research study aimed to: (1) identify the ICCT client clusters which generate higher costs with medical and pharmaceutical supplies (MPSs) used by professionals; (2) identify MPSs that generate higher costs; and (3) identify the association between costs with MPSs and length of hospital stay, clients' age and ICCTs.

\section{Background}

The National Health Service (NHS) is a very complex and tributary structure composed of a wide range of social, political, economic, and environmental variables. Everything can influence the populations' health status, so everything will influence the health care provision system and, simultaneously, the associated costs. Due to the increased life expectancy and incidence of chronic diseases, Portugal will have to optimize its long-term care responses, particularly for rehabilitation and self-care, but also for the treatment of other diseases in non-acute stages which traditionally were only treated in hospital environment. A study presented by the OECD indicates that total spending on health will double by 2050 (OECD, 2013).

The countries' economic difficulties, particularly in terms of budget constraints, pose new challenges to the strategic management of health care organizations, namely in terms of becoming more efficient and creating value for their clients (Escoval, 2008). Primary healthcare models, where nurses may assume new roles, particularly in chronic disease management, will allow better control of expenditure, thus ensuring the sustainability of the NHS (Fundação Calouste Gulbenkian, 2014; OECD, 2015). The provision of hospital care at home is already a reality in many countries and several studies have shown that it is equally effective, increases patient satisfaction, reduces healthcare-associated infections, and is more costeffective (Shepperd et al., 2009). The use of primary healthcaremodels will decrease the mean length of stay and reduce costs in the extent that "it has been estimated that $30 \%$ of hospital activity in Portugal could be done in the community, and around EUR 20 million per year could be saved by transferring more nursing care out of hospitals" (OECD, 2015, p. 34). Based on this context, cost identification and management, and a better knowledge of the populations are essential for an improved management of public resources.

\section{Research question}

Therefore, the research question seeks to identify clusters generated by the costs with medical and pharmaceutical supplies used by ICCTs in their interventions, and establish associations between 
these costs and other variables such as: teams, length of hospital stay in days, and clients' age.

\section{Methodology}

This is an exploratory, correlational and cross-sectional study. The sample was temporal and included 181 clients who received care from four ICCTs, located in Northern Portugal, between 1 September and 31 December 2012. With regard to gender, 100 clients were female and 81 were male, with a mean age above 71 years. The mean length of hospital stay was 63.5 days, and most cases were referred by the hospital.

The healthcare team is multidisciplinary (nurses, physical therapists, social workers, nutritionist, physician, health assistants), with increased competences in several areas (wound care, palliative care, rehabilitation). Nurses represent more than $60 \%$ of the professionals in all teams, and most of them are specialist nurses.

Data were collected from the clinical information systems and management planning and control systems used by the institution, the costing system and an e-form designed for this purpose.

Data were analyzed using the required statistical techniques and tests to assess the relationship between the various variables. We used the cluster analysis, which is an exploratory multivariate analysis technique, to group cases or variables in homogeneous clusters according to the similarities and differences between them (Marôco, 2010).
The identified clusters, through large dimensions of analysis, were compared among them and with the study variables. We used the two-step method (Statistical Package for the Social Science [SPSS] software, version 21.0) as algorithm for its ability to compute categorical and continuous variables and automatically select the number of clusters.

Prior to the study, we requested permission to the Board of Directors of the institution, which granted it. We complied with all the ethical standards and respected the rights of those involved in the whole process. No files with personal data of the clients involved resulted from data processing and analysis since these data were electronically anonymized.

\section{Results}

In the case under analysis, this methodology identified two clusters with a profile of cohesion and separation of Good, as it showed a value greater than 0.5. This value indicates that the variables in each cluster are located in the center region, which means that they are highly similar and that the similarities between both clusters are low, demonstrating the quality of each cluster.

Clusters were analyzed based on the variables that define the type and price of the supplies used by the ICCTs in the clients. The combination of the variables resulted in two clusters. For the identification of both clusters, we took into account the 10 main predictors described in the figure below.

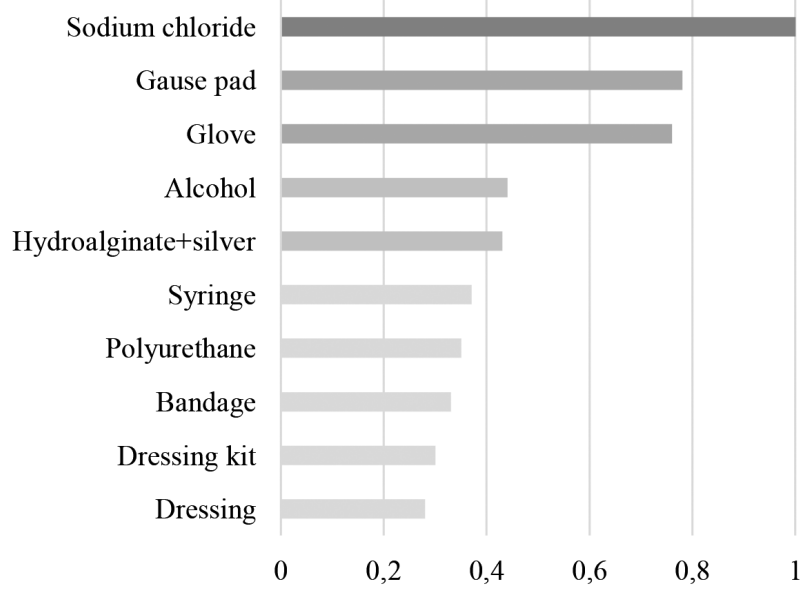

Figure 1. The 10 main predictors in the clustering process. 
This type of supply, which better predicts the model, is mainly related to clients with higher morbidity, with multiple complex wounds requiring longer treatments over several days. The supplies used in these clients have high costs associated due to the number of units used (prolonged treatments related to several foci of attention) or the high cost per unit. Sodium chloride solution is the main predictor, being mainly used for washing wounds and ulcers. Regardless of the use of other supplies, it is always used in wound care procedures.

Each of the abovementioned clusters identifies the financial impact of using MPSs in clients referred by ICCTs according to the differences between them and their specific characteristics. Thus, taking this context into account and after identifying the reason for referral and the type of supply associated with each one, we created two clusters: higher consumption of wound care supplies, and lower consumption of wound care supplies.

The largest cluster - lower consumption of wound care supplies - includes 138 cases (86.8\%), and the smallest cluster - higher consumption of wound care supplies - includes only 21 cases (13.2\%), with a ratio of 6.57 of the size of the largest cluster to the smallest cluster.

When we analyzed the 10 main predictors, we observed that the MPSs with a greater impact on costs are supplies often used in wound care, especially in complex and hard-to-heal wounds. Sodium chloride is used for cleaning wounds, so the more complex are the wounds, the more supplies will be used. Polyurethane or silver-releasing hydroalginate are dressings used to treat infected wounds.

The analysis was performed based on the variables, which consisted in the 10 predictors, whose consumption determines the allocation of clients to one cluster or the other, through the calculation of the median, the quartile and the interquartile range, in general and separately for both clusters.

From the comprehensive analysis of the behavior of the different variables in both clusters, two aspects should be highlighted. First, we found two types of median distribution: one distribution where the medians of the cluster of greater consumption of wound care supplies always obtains higher values than those of the overall median; and another distribution concerning the cluster of lower consumption of wound care supplies in which, with the exception of the median for the variables bandage cost and dressing cost, which is equal to the overall median, all medians in the other variables are below the overall median value.

The second aspect is associated with the difference between clusters. When we analyzed the interquartile range (IQR) in both clusters, we observed that the distance is clearly visible in the diagram concerning the cluster of higher consumption of wound care supplies. The medians of the 10 main variables that define the model lie outside the interquartile range. Clearly, the medians for the cluster of lower consumption of wound care supplies are within that range or near its threshold. We can therefore assume that, in the identity matrix of each cluster, in addition to the relative importance of the different variables, the cluster of higher consumption wound care supplies will consist of more extreme cases, i.e. cases in which the values of the variables are at one end of the range of values found (clients that represent very high costs).

In order to consolidate these general observations, we performed a comparative analysis between both clusters, for each variable, using the overall results of that variable as reference, as shown in the table below.

Table 1

Median, quartile and interquartile range of the main predictors in the clustering process

\begin{tabular}{|c|c|c|c|c|c|c|c|c|c|c|c|c|}
\hline \multirow{2}{*}{ Predictor } & \multicolumn{4}{|c|}{ Both clusters } & \multicolumn{4}{|c|}{$\begin{array}{l}\text { Higher consumption } \\
\text { of wound care supplies }\end{array}$} & \multicolumn{4}{|c|}{$\begin{array}{c}\text { Lower consumption } \\
\text { of wound care supplies }\end{array}$} \\
\hline & Median & $\begin{array}{c}\text { Quartile } \\
75\end{array}$ & $\begin{array}{c}\text { Quartile } \\
25\end{array}$ & $\begin{array}{l}\text { Interquartile } \\
\text { Range }\end{array}$ & Median & $\begin{array}{c}\text { Quartile } \\
75\end{array}$ & $\begin{array}{c}\text { Quartile } \\
25\end{array}$ & $\begin{array}{l}\text { Interquartile } \\
\text { Range }\end{array}$ & Median & $\begin{array}{c}\text { Quartile } \\
75\end{array}$ & $\begin{array}{l}\text { Quartile } \\
25\end{array}$ & $\begin{array}{l}\text { Interquartile } \\
\text { Range }\end{array}$ \\
\hline $\begin{array}{l}\text { Cost }(€) \\
\text { Sodium } \\
\text { chloride }\end{array}$ & 2.2 & 11.62 & 0.33 & 11.29 & 47.44 & 96.32 & 23.46 & 72.84 & 1.22 & 6.59 & 0.29 & 6.3 \\
\hline $\begin{array}{l}\text { Cost }(€) \\
\text { Gauze } \\
\text { pads }\end{array}$ & 0.19 & 2.47 & 0.09 & 2.38 & 21.63 & 42.02 & 7.07 & 34.95 & 0.16 & 1.51 & 0.08 & 1.43 \\
\hline
\end{tabular}




\begin{tabular}{|c|c|c|c|c|c|c|c|c|c|c|c|c|}
\hline $\begin{array}{l}\text { Cost }(€) \\
\text { Gloves }\end{array}$ & 1.11 & 3.34 & 0.24 & 3.1 & 8.10 & 12.70 & 5.76 & 6.94 & 0.83 & 2.20 & 0.20 & 2 \\
\hline $\begin{array}{l}\text { Cost }(€) \\
\text { Alcohol }\end{array}$ & 1.79 & 5.92 & 0.36 & 5.56 & 15.78 & 34.03 & 4.33 & 29.7 & 1.49 & 4.28 & 0.31 & 3.97 \\
\hline $\begin{array}{l}\text { Cost }(€) \\
\text { Silver- } \\
\text { releasing } \\
\text { Hydroalgi- } \\
\text { nate }\end{array}$ & 2.33 & 3.46 & 1.18 & 2.28 & 157.47 & 259.37 & 3.18 & 256.19 & 2.15 & 3.46 & 1.18 & 2.28 \\
\hline $\begin{array}{l}\text { Cost }(€) \\
\text { Syringes }\end{array}$ & 0.03 & 0.13 & 0.01 & 0.12 & 0.68 & 4.76 & 0.03 & 4.74 & 0.02 & - & - & - \\
\hline $\begin{array}{l}\text { Cost }(€) \\
\text { Polyure- } \\
\text { thane }\end{array}$ & 0.69 & 6.76 & 0.35 & 6.41 & 30.42 & 87.09 & 2.75 & 84.34 & 0.62 & - & - & - \\
\hline $\begin{array}{l}\text { Cost }(€) \\
\text { Bandages }\end{array}$ & 0.27 & 0.41 & 0.14 & 0.27 & 0.67 & 40.35 & 0.27 & 40.08 & 0.27 & - & - & - \\
\hline $\begin{array}{l}\text { Cost }(€) \\
\text { Wound } \\
\text { care kit }\end{array}$ & 1.50 & 11.39 & 0.47 & 10.92 & 45.57 & 75.11 & 33.34 & 47.77 & 0.81 & 6.71 & 0.41 & 6.3 \\
\hline $\begin{array}{l}\text { Cost }(€) \\
\text { Dressings }\end{array}$ & 0.11 & 0.17 & 0.06 & 0.11 & 0.19 & 10.18 & 0.10 & 10.08 & 0.11 & - & - & - \\
\hline
\end{tabular}

\section{Costs with sodium chloride}

With regard to the MPS costs with sodium chloride, we found that this is the strongest predictor (1.00). The overall cost with this product in both clusters shows data variability in this context. In the cluster of higher consumption of wound care supplies, data range lies near the upper quartile which shows, once again, a high data variability. This fact demonstrates that this cluster includes the most extreme clients, i.e. those who represent higher costs. In the cluster of lower consumption of wound care supplies, the IQR shows data variability, but with much lower costs since it is below the overall IQR, thus confirming that this cluster has the lowest consumption of sodium chloride.

\section{Costs with gauze pads}

The MPS costs with gauze pads occupy the second position, taking into account the predictors' importance (0.78). The IQR is close to the upper quartile, which shows data variability in both clusters. In the cluster of higher consumption of wound care supplies, data range lies near the Q75 range which shows, once again, a high data variability, but with much higher median values, thus corroborating that these are indeed the clients who represent the highest costs. In the cluster of lower consumption of wound care supplies, the IQR shows, once again, data variability, confirming that this cluster has the lowest consumption of gauze pads since the median and quartile values were much lower.

\section{Costs with gloves}

The MPS costs with gloves occupy the third position, taking into account the predictors' importance (0.44). The overall cost with this product in both clusters shows data variability in this context. In the cluster of higher consumption of wound care supplies, the low data range shows low data variability in this context and that the cost with this product is similar in every client. In the cluster of lower consumption of wound care supplies, the IQR shows that, similarly to the previous clusters, there is data variability, since the cost with this product differs among clients. Despite this, it confirms that this cluster has the lowest consumption of gloves since the IQR is lower than the overall median value.

\section{Costs with alcohol}

The MPS costs with alcohol occupy the fourth position, taking into account the predictors' importance (0.44). The overall cost with this product in both clusters shows data variability in this context. In the cluster of higher consumption of wound care supplies, the IQR lies close to the upper quartile, which shows high data variability in this context. In the cluster of lower consumption of wound care supplies, the IQR lies close to the upper quartile which also data variability shows in this cluster, but with lower values, confirming that this cluster is composed of clients who require the use of less alcohol. 


\section{Costs with silver-releasing hydroalginate}

The MPS costs with silver-releasing hydroalginate occupy the fifth position as predictor of the model (0.44). The overall cost with this product in both clusters shows low data variability in this context. In the cluster of higher consumption of wound care supplies, the IQR lies close to the Q75 range, which shows high data variability in this context. This product has high costs associated, being the largest among the 10 main predictors. In the cluster of lower consumption of wound care supplies, the IQR shows that data variability is the lowest and with substantially lower costs than the previous cluster.

\section{Costs with syringes}

With regard to the MPS costs with syringes, we found that this predictor occupies the sixth position (0.36). The overall cost with this product in both clusters shows data variability in this context. In the cluster of higher consumption of wound care supplies, data range lies near the Q75 range which shows a high data variability, as in the overall context. In the cluster of lower consumption of wound care supplies, we were not able to calculate the quartiles, which confirms the lack of data variability. In this cluster, the median value is similar to that of the overall context, which corroborates the fact that the cluster of higher consumption of wound care supplies shows the highest costs and greatest variability.

\section{Costs with polyurethane}

With regard to the MPS costs with syringes, we found that this predictor occupies the seventh position (0.34). The overall cost with this product in both clusters shows, once again, data variability in this context. In the cluster of higher consumption of wound care supplies, the IQR shows, similarly to the overall context, a wide distance between data near the Q75 range. In the cluster of lower consumption of wound care supplies, we were not able to calculate the quartiles, which confirms the lack of data variability in this cluster, taking into account that the median is similar to that of the overall context. Once again, we found that the cluster of lower consumption of wound care supplies shows substantially lower costs.

\section{Costs with bandages}

The MPS costs with bandages occupy the eighth position, taking into account the predictors' importance (0.32). The overall cost with this product in both clusters shows less data variability in both clusters than the previous variables, given the distance to the upper quartile. In the cluster of higher consumption of wound care supplies, the IQR is high and very close to the upper quartile, which shows high data variability in this context, that the costs with this type of supply may differ between clients, and that it has very high costs. In the cluster of lower consumption of wound care supplies, we were not able to calculate the quartiles or the corresponding range, which also corroborates data homogeneity. This confirms the low use and cost of this supply in this cluster, thus allocating its clients to the cluster of lower consumption of wound care supplies.

\section{Costs with dressing kits}

The MPS costs with dressing kits occupy the ninth position in the predictors' importance $(0.31)$. The overall cost with this product in both clusters shows data variability in this context. In the cluster of higher consumption of wound care supplies, data range is still high, even with an IQR closer to the center, which shows that, in this cluster, all clients represent high costs with this supply. In the cluster of lower consumption of wound care supplies, the IQR is close to the upper quartile, showing data variability in this cluster as well. This can be explained by the fact that the clients in this cluster, regardless of the existence of wound patients, do not have wounds as complex as those in the cluster of higher consumption of wound care supplies, thus explaining the lower median value of the costs.

\section{Cost with dressings}

The MPS costs with dressings occupy the tenth position in the predictors' importance (0.29). The overall cost with this product in both clusters shows data variability in this context. In the cluster of higher consumption of wound care supplies, the IQR is high and very close to the Q75 range, which shows high data variability in this context. In the cluster of lower consumption of wound care supplies, we were not able to calculate the quartiles or the corresponding range, which also corroborates data homogeneity. This confirms the low use and cost of this supply in this cluster, thus allocating its clients to the cluster of lower consumption of wound care supplies. 


\section{Discussion}

In this analysis, we sought to identify clusters of ICCTs' clients, taking into account the costs with the MPSs used in the interventions.

The cluster analysis showed that the MPSs costs are always higher than the overall median in the client cluster with the highest consumption of wound care supplies. With regard to the cluster of lower consumption of wound care supplies, except for the median value of the variables related to the costs with bandages and costs with gauze pads, whose values are equal to the overall median, all median values of the remaining variables are below the overall median value. Another relevant observation refers to the difference between clusters. When we analyzed the IQR in both clusters, we observed that the cluster with more extreme cases showed higher costs with wound care supplies, i.e. the values of the variables in this cluster are clearly at one end of the range of values recorded.

Taking into account the impact of wound care and the significant association with the length of hospital stay, with $11.7 \%$ of the mean variation in the total cost with MPSs being determined by the number of days of hospital stay, the identification of those clusters is essential for predicting the costs associated with the population's characteristics, which should influence funding.

One of the limitations of this study was the fact that it was conducted in a single health unit. Another limitation was related to the temporal sampling technique, i.e. the period selected may not be representative of the entire year. However, it should be noted that the occupancy rate in this period was similar to the annual occupancy rate, as well as the length of hospital stay and clients' age. Thus, the possibility of sampling error was minimized.

\section{Conclusion}

We found that ICCTs, when analyzed based on the costs with MPSs, provide more expensive care to around $13 \%$ of their clients. Given the characteristics related to more complex wounds, interventions must aim at preventing this type of complications, namely those related to the prevention of pressure ulcers, since it has been proven that, in addition to reducing costs with MPSs, they also reduced the length of hospital stay and, consequently, overall costs.

We believe that this study can contribute to better understand the costs associated with the provision of continuous care at home in the extent that this type of care showed lower costs than the costs associated with hospital care. We believe that conditions must be created to allow patients to remain within the family. Although these conditions relate to healthcare in particular, support care must be ensured as well. This will allow for a greater access of the population to the NHS, which will become simultaneously more accessible and efficient, thus contributing to its financial sustainability.

The identification of clusters of ICCT clients contributed to a better understanding of the population, which in turn allows for the elaboration of a contracting and financing model based on the complexity of the population being cared for, and on the performance of the teams providing care.

\section{References}

Escoval, A. (2008). Inovação, sustentabilidade e valor em saúde. In A. Escoval (Ed.), Financiamento: Inovação e sustentabilidade (pp. 10-23). Lisboa, Portugal: Associação Portuguesa para o Desenvolvimento Hospitalar.

Fundação Caloustre Gulbenkian . (2014). Um futuro para a saúde: Todos temos um papel a desempenbar. Lisboa, Portugal: Gráfica Maiadouro.

Instituto Nacional de Estatistica. (2012). Saúde e incapacidades em portugal 2011. Lisboa, Portugal: Autor.

Marôco, J. (2010). Análise estatística com o PASW statistics (exSPSS). Pêro Pinheiro, Portugal: Report Number.

Organisation for Economic Co-operation and Development. (2011). Health reform: Meeting the challenge of ageing and multiple morbidities. doi:10.1787/9789264122314-en

Organisation for Economic Co-operation and Development. (2013). Dépenses publiques de soins de santé et de soins de longue durée: Une nouvelle série de projections. Paris, France: Autor.

Organisation for Economic Co-operation and Development. (2015). Reviews of bealth care quality: Portugal 2015: Raising standards. Paris, France: Autor.

Observatório Portugês dos Sistemas de Saúde. (2015). Acesso aos cuidados de Saúde: Um direito em risco?: Relatório de primavera. Lisboa, Portugal: Autor. 
Shepperd, S., Doll, H., Augres, R., Clarke, M., Kalra, L., Ricanda, N., ... Wilson, A. (2009). Avoiding hospital admission through provision of hospital care home: Systematic review and meta-analysis of individual patient data. Canadian Medical Association journal, 180(2), 175-182. doi:10.1503/ cmaj.081491 